\title{
Factorial structure of aerobics athletes' fitness
}

\author{
Shepelenko T.V. ${ }^{1}$, Kozina Zh.L. ${ }^{2}$, Cieślicka M. ${ }^{3}$, Prusik K. ${ }^{4}$, Muszkieta R. ${ }^{5}$, Sobko I.N. ${ }^{6}$, Ryepko O.A. ${ }^{2}$, \\ Bazilyuk T.A. ${ }^{7}$, Polishchuk S.B. ${ }^{2}$, Osiptsov A.V. ${ }^{8}$, Kostiukevych V.M. ${ }^{9}$ \\ ${ }^{1}$ Ukrainian State University of Railway Transport, Ukraine \\ ${ }^{2}$ H.S. Skovoroda Kharkiv National Pedagogical University, Ukraine \\ ${ }^{3}$ Kazimierz Wielki University in Bydgoszcz, Poland \\ ${ }^{4}$ Academy of Physical Education and Sports in Gdansk, Poland \\ ${ }^{5}$ Nicolaus Copernicus University in Torun, Poland \\ ${ }^{6}$ Kharkov National Economic University, Ukraine \\ ${ }^{7}$ Kiev National University of Technology and Design, Ukraine \\ ${ }^{8}$ Mariupol State University, Ukraine \\ ${ }^{9}$ Mykhailo Kotsyubynskyi Vinnitsa State Pedagogical University, Ukraine
}

\begin{abstract}
Purpose: $\quad$ The purpose of the research is to develop an algorithm of teams' formation in sport aerobics and to define factorial structure of athletes' fitness.

Material: $\quad$ in the research sport aerobics' athletes $(n=19)$ participated. All athletes are members of Kharkiv national team (Ukraine). All athletes underwent complete medical examination. The functional condition of an organism (arterial blood pressure, indicators of a variability of the rhythm of the heart, treadbahn testing), psycho-physiological state (time's determination of simple and complex reaction) were defined. The physical development and physical fitness and stability of vestibular system were also defined. The factorial and cluster analysis were used.

Results: $\quad$ The algorithm of teams' formation in sport aerobics is developed for performances in various competitive categories. The algorithm contains all stages of standard procedure of the factorial and cluster analysis. In the factorial analysis the individual factorial values were also defined.

Conclusions: The obtained data are recommended to be used at teams' formation for performances in various competitive categories: team formation for pair and group performances. The general and individual factorial structure of athletes' complex fitness is defined. It is possible to select athletes with similar qualities and with different qualities for the mixed performances. The determination of individual factorial structure of fitness permits to estimate objectively variants of athletes' formation in groups.

Keywords: individualization, algorithm, aerobics, factorial, cluster.
\end{abstract}

\section{Introduction}

The aerobics is a difficult and emotional sport. In aerobics are used elements from artistic and rhythmic gymnastics and acrobatics. A lot of attention is paid to choreography. In programs of mixed pairs, trio and group more attention is paid to interaction between partners. The following categories of performances are provided in aerobics: individual male, individual female, mixed pairs, trio and group (5 athletes). The aerobic dancing (aerodance) and the gymnastic platform (aerostep) are also used. The versatile character of sport aerobics creates certain difficulties in planning of training process. The big complexity is also caused by optimum selection of athletes for group performances.

In scientific literature nowadays a lot of attention is paid to aerobics as mean of health promotion and improvement of people's functional condition.

Shypulo I.P. [1] proved the increase of aerobic exercises' efficiency of girls' motor fitness at the extracurricular institutions. The author defined the most informative indicators of girls' physical fitness. The analytical graphic model for forecasting and carrying out the quantitative and high-quality control of girls' fitness

(c) Shepelenko T.V., Kozina Zh.L., Cieślicka M., Prusik K. Muszkieta R., Sobko I.N., Ryepko O.A., Bazilyuk T.A.,

Polishchuk S.B., Osiptsov A.V., Kostiukevych V.M., 2017 doi:10.15561/18189172.2017.0606 level is created. The author concluded about possibility of results forecasting of aerobics exercises. The method of aerobics exercises which consists of five stages is recommended to perform. Its main feature is constant objective control of exercises' efficiency.

Beliak Yu.I. et al. [2] offered the dispensing method of physical activity in aerobics classes for students. The energetic value for each zone of loads intensity was determined on the basis of correlation between the heart beats rate and consuming of oxygen. The evaluation component of this dispensing method of loads permits to use it computer programs. It can be also easily modified for load distribution on other types of recreational fitness.

Bryukhanova N.A. et al. [3] revealed reaction of students' heart rate on the increasing of musical speed. The authors recommend to use the increasing of intensity only in limited scope during trainings: the increasing of musical speed up to $142-145$ beats per minute or heights of the step platform up to 20 centimeters.

Gurieieva A.M. et al. [4] described the factor structure of girls' physical condition at the beginning of academic year. The authors offered rational balance of physical skills' development methods necessary for recreational aerobics' program creation. The authors managed to define the most important factors influencing on the girls' health condition of the first year of study. The factor analysis 
permitted to specify the correlation of methods which are intended for physical skills development.

Golod N.R. [5] selected basic provisions of the comprehensive program of physical rehabilitation for students of special medical group. The program of rehabilitation included: change of lifestyle; morning hygienic exercises; kinesiatrics (yoga, functional training); aerobic exercises (swimming, Nordic Walking, jogging, recreational aerobics); massage.

Thus, a lot of scientific researches devoted to recreational aerobics are closely intertwined with problems of sport aerobics. Therefore they can be applied in the training process of athletes in sport aerobics. However there are not many scientific researches devoted to the problems of sport aerobics.

Chen L.Y. [6] offered the method of motor actions' reconstruction in aerobics based on three-dimensional vision of motor action. The author offers to use the computer visual recognition technology for extraction of specific point of athlete's body image. It gives the opportunity to obtain the main features of athlete's body shape. Then the evaluation of motor action from the four points in the three-dimensional space is done. The results of modeling testified that offered method can improve considerably the motor action's evaluation efficiency and its correction in the course of training.

Fan C. [7] demonstrated that one of basic elements in sport aerobics is jump. At the same time the jump's height, speed of jumping squat and position of the athlete in space are also important. The author offered the jumps training technique in aerobics which involves using of special exercises for increase the ability of body control in space.

Hu C. F. et al. [1] point that the main sense of aerobics consists in manifestation of beauty of art and the motor action. The aerobics gives the chance to enjoy the beauty of motor compositions.

Jiang G. P. et al. [2] investigated jumps with obstacles in sport aerobics. The authors have determined that in a phase of take-off there are two peak phases of manifestation of the maximum strength of a hip and a shin. The peak phase of hip muscles' tension is appeared in a preparatory phase of a jump, and of shin muscles' tension is appeared in a take-off phase. In phase of action in the air the various segments of a body exert various impacts on the effect of the turn. In a landing phase the maximum rotary moment of a coax is much more, than at other joints. The author recommends using the obtained data in training technology of jumps in aerobics.

Li A. [10] analyses the physiological and psychological features of high-class athletes in sport aerobics who were traumatized. The author developed the scientific basis of training process in sport aerobics and rehabilitation after sport injuries. The author specifies that reasons of sport injuries are difficult and multifaceted. The author analyzed the psychological reasons of sport injuries. It gives the opportunity to facilitate the effective rehabilitation of athletes.

Li C. et al. [11] carried out the factorial analysis of anklebone injuries' reasons in sport aerobics training. The authors suggest reducing of unnecessary classes of aerobics for training process' optimization.

Huang W.Y. et al. [12] studied athletes' heart rate variability in aerobics with use of the telemetric monitor of heart rate continuous registration (Polar RS800). The conclusion was drawn that age, professional qualification, heart rate and gender influence on athletes' heart rate variability during increase of loads.

Sang G.Q. [13] conducted a sociocultural research of aerobics development. The author specifies that aerobics is a new type of the sport program. The aerobics acquired high popularity grace to its unique modern attractions. The author researched correlation between aerobics and modern society and analyzed different types of the social and economic factors appeared with aerobics development based on careful examination of spiritual and cultural elements in aerobics development and its social impact.

Shi W.Y. [14] conducted researches on development and application of aerobics training courses. The author testified that hyper media technologies in sport aerobics training courses have strong impact on study. Technologies contain the multimedia material oriented on target functions of sport practice training. Such material promotes the correct organization of educational information. Such approach is useful for sport practice.

Wang M. [15] analyzed correlation between efficiency of study in strength exercises and level of athletes' physical fitness. Normalization of athletes' technical actions in aerobics is closely connected to the level of their physical fitness. It is appeared in technical elements when athletes execute falling. The correlation between strength training and athletes physical monitoring is analyzed. It can be used for increase the strength opportunities and physical fitness.

Zarebska A. [16] revealed that dancing aerobics provides sufficient incentives for increase in explosive strength. It influences on jumps' height. The author revealed the genetic conditionality of jumping ability's training effect.

Yan F.F. [17] offered method of decorating the complete sets of competitive aerobics in trio (one of categories of sport aerobics). The author demonstrated influence of performances in trio on development of competitive aerobics. The results testify that the competitive aerobics has the following aspects: sportswear, temperament, body shape, physical trait and others.

Xiang F.F. et al. [18] analyzed the importance of strength for keeping the body position in space. The authors offer cautions concerning strength training in aerobics. In aerobics the speed, rhythm, amplitude, athlete's body center of gravity are important. The pose can reflect art achievements of athletes. The athlete's pose influences on general judicial evaluation. The authors analyzed importance of strength development from the point of view of body's position.

In other researches it is possible to select solutions of the following problems of athletes fitness: programs' development directions permitting to keep physical shape 
effectively [19]; differentiation of relocation methods in dancing games [20]; motivational aspects of success achievement [21, 22]; mechanical parameters of jumps [23] influence of interval fitness program and interval study program on aerobic and anaerobic physiological indicators [24].

Developing of athletes training programs presuppose such elements in sport aerobics: optimization of physical activities [25] and didactic basics of a training [26, 27]; choice of adequate tests and pedagogical control [28, 29]; periodization of training process [30] and competitive activity [31, 32]; factors of athletes success [33, 34] and choice of optimum parameters of the movement $[35,36]$.

Thus, there is a problem of training creation process in sport aerobics. The greatest attention is paid to physical training of athletes, problems of traumatism and rehabilitation after injuries, to the analysis of biomechanical structure of various movements, to use of interactive technologies. However, the problem of individual approach and a teams' formation for group performances in various competitive categories of sport aerobics is less researched. Thus, in modern sport aerobics the principles of athletes division according to groups for teams' formation have descriptive character. There is no emphasis on quantitative models. Also the principles of mathematical and statistical modeling aren't applied. In literary data there are no accurate recommendations about aerobics athletes training in respect of individual psychophysiological opportunities and typological features.

The purpose of the article is to develop an algorithm of teams' formation in sport aerobics and to define factorial structure of athletes' fitness.

\section{Material and methods}

Participants. in a research the athletes $(\mathrm{n}=19)$ from the sport aerobics national team (Kharkiv, Ukraine) have participated.

Organization of a research. The following methods were used: methods of functional definition of athletes' organism condition (arterial blood pressure, indicators of variability of the heart's rhythm, treadbahn testing) psycho-physiological methods of research (time's determination of simple and complex reaction in various modes of signaling); methods of physical development's definition and physical fitness; method of vestibular tolerance's definition.

The variability of the heart's rhythm was used for the analysis of vegetative regulation of heart activity.

The record of a signal was carried out on the portable cardiographic equipment «Cardiolab +», (Computer electrocardiograph «Cardiotest» permits to register 12 channels standard ECG, ECG in the lead system by Neb and Frank. For the indicators' analysis is used Dialog box «Complex» Dialog box «Lens» http://www.dx-sys.com. ua/en/products/). Its basis is made by $3 ; 6 ; 12$ channel cardiograph + the Cardio CE phonocardiograph + on the basis of a notebook (or the personal digital assistant) PAQ 3870. The Polar model monitor of heart rate continuous registration with appropriate software was also used. The record was realized for 5 minutes in lying position after 5 -minute rest.

The subsequent processing of cardiointervals permitted to define a row of statistical characteristics of variability of the rhythm of the heart [37]:

As indicators of heart beats rate we found:

1. Mo (mode of RR-intervals' duration) the most frequent interval between teeth RR (sec.);

2. AMo (amplitude of mode of duration of RRintervals) - percentage of intervals' quantity (the most frequent) to the total quantity of the measured intervals (in our case we used 50 RR-intervals) (\%);

3. $\Delta \mathrm{x}-$ variation range of RR-intervals' duration: there is difference between the highest and the least value of RR-intervals (sec.);

4. Index of tension (conv. un) of regulatory mechanisms (IT) we found by formula:

$\mathrm{IT}=\mathrm{AMo} / 2 \mathrm{Mo} \bullet \Delta \mathrm{x} \quad(1)$,

Where $\Delta \mathrm{x}-$ is the value of variation range of RRintervals' duration (sec.);

Mo - mode of RR-intervals' duration (sec.);

AMo - amplitude of mode of duration of RR-intervals (\%).

In the analysis of heart rate indicators we were guided by the fact that indicators of a heart rate reflect a different contribution of sympathetic and parasympathetic branches of the autonomic nervous system to the process of heart activity regulation. The mode of RR-intervals' duration (Mo) indicates resultant effect of regulatory influences. It reflects the steadiest functioning level in these conditions. The variation range reflects the range of possible deviations option of casual process. The variational range is defined by expressiveness of respiratory oscillations of a heart rate. Therefore this index is considered as the indicator of activities of an closed-loop control. The amplitude of mode of duration of RR-intervals (AMo) permits to judge about activity of closed-loop control. Thus, increase of AMo duration of RR-intervals and IT witness about tonus increase of sympathetic branch of the autonomic nervous system. Increasing of variation range of RR-intervals' duration witnesses about increase of parasympathetic branch influence of the autonomic nervous system [37].

In our research was also conducted testing by time's definition of simple and complex reactions to sound and visual stimuli. Time of complex reaction was determined by testing with feedback. In a testing of time's definition of difficult visual and motor reaction with feedback were determined: time of latent period reaction; average quadratic deviation; quantity of mistakes; time of the minimum exposition; time to reach to the minimum exposition [38].

Our research carried out the testing to define the time of simple and complex reactions to sound and visual stimuli. Time of complex reaction was determined by testing with feedback. Time of the latent period of reaction, an average quadratic deviation, and quantity of mistakes, time of the minimum exposition and time of reach the minimum exposition were defined by time definition of complex 
visual and motor reaction with feedback [38].

The vestibular stability was determined with the help of Barany mechanical chair. Rotation of chair was ensured by hand during $20 \mathrm{sec}$ at speed of 2 r.p.sec ${ }^{-1}$. After every 2 sec. we registered heart beats rate (HBR) with the help of photoelement equipment. HBR was also registered after rotation during $10 \mathrm{sec}$, after every $2 \mathrm{sec}$. Increase of HBR before and after rotation was considered as proper reaction to rotation. It is activation of sympathetic branch of autonomic nervous system. Decreasing of HBR before and after rotation was considered as inappropriate reaction to rotation. It is activation of parasympathetic branch of autonomic nervous system (motion sickness). In case of data analysis the HBR indicators on the $2^{\text {nd }}$ sec after the beginning of rotation were selected. The indicators after rotation were also selected [37].

Statistic analysis. Digital material was processed by means of traditional methods of mathematical statistics. The arithmetic average value $\mathrm{X}$, an average quadratic deviation of $\mathrm{S}$ (a standard deviation) was determined by each index. The factorial and cluster analysis of testing indicators were also carried out. The factorial analysis of testing indicators was carried out during the primary materials processing. The obtained data processed by means of Excel and SPSS software. Differences considered reliable at significance value of $p<0,05$.

\section{Results}

We developed an algorithm of definition of individual factorial structure of athletes' fitness for teams' formation for competitive categories in sport aerobics.

The algorithm consists of the following stages:

- conducting of athletes' testing, which includes set of tests (not less than 10);

- definition of the general structure of athletes' fitness. Definition of major factors and drawing up their characteristic;

- determination of individual factorial values structure of athlete's fitness. It is necessary to notice that this stage is extremely seldom applied in sport's scientific researches. As a rule, most of researchers define the general factorial structure of athletes' fitness. However determination of individual values of factorial structure of fitness is important for creation a better understanding of athlete, planning of his training, selection of partners etc;

- carrying out the hierarchical cluster analysis of testing indicators. Selection of teams in sport aerobics on the basis of the groups formed as a result of the cluster analysis;

- drawing up characteristics of the formed groups of athletes. Creation of programs for performances in various competitive categories. Development of training programs.

We investigated the factorial analysis of indicators for definition of the general and individual structure of athletes' fitness as one of fundamental components of this algorithm.

In structure of athletes' complex fitness 4 major factors were defined: Cattell's method was used. For the characteristic of each factor its indicators were analyzed.

The first factor consists of following indicators $(28,6 \%$ of general total dispersion) (tab. 1): HBR on the $2^{\text {nd }} \mathrm{sec}$ at rotation on Barany's chair $(r=0,95)$, HBR in $90 \mathrm{sec}$ of rest after performance of a standard load on the treadbahn $(\mathrm{r}=0,94)$, HBR after the rotation on Barany's chair $(\mathrm{r}=$ $0,93)$, an indicator of HBR average value in heart rate $(r=$ $0,95)$, HBR in $10 \mathrm{sec}$ after rotation on Barany's chair ( $\mathrm{r}=$ $0,88)$, HBR of the rest $(r=0,68)$.

The first factor consists of indicators reflecting the level of a regulation of vegetative balance from the central nervous system (CNS). The increasing of HBR (at rest, an average value in heart rate, at the beginning and after the rotation on Barany's chair) is pointed to activization of sympathetic branch of the autonomic nervous system.

The increasing of $\mathrm{HBR}$ in response to rotation demonstrates proper response of the vestibular system to rotation. It is followed by activization of sympathetic branch of the autonomic nervous system. On the other hand, increasing of HBR of rest and HBR average values in heart demonstrates activization of sympathetic branch of the autonomic nervous system. It can reflect the insufficient level of athletes' functional training. In our case increasing of HBR at rest can be regarded as fast activization of power supply systems of muscular activity in response to the beginning of testing. Testing is perceived by an organism as a stimulus. The organism reacts to this stimulus as well as to muscular work.

Such fast activization of power supply mechanisms, fast getting "degree of readiness" demonstrates adequate regulation of vegetative balance from a CNS. Also it demonstrates high reactivity of sympathetic branch of the autonomic nervous system.

This factor included indicators of nervous processes mobility (time to reach to the minimum exposition of a signal, time of the minimum exposition of a signal) ( $\mathrm{r}$ $=-0,57 ;-0,53$ ). It is established that indicators of nervous processes mobility correlate with indicators of activity of sympathetic branch of the autonomic nervous system. It can be explained with the fact that also the activity of sympathetic branch of the autonomic nervous system is necessary for implication of nervous system mobility. Based on the above stated, the first factor was called "sympathicotonia" (fig. 1).

The second factor consists of the following indicators (28,5\% of general total dispersion): age $(\mathrm{r}=-0,92)$, body weight $(r=0,85)$, wrist strength $(r=0,81)$, back strength $(r=0,72)$, body length $(r=0,68)$ (tab. 1$)$. Indicators of the second factor mainly reflect the level of development of strength abilities and absolute strength. An exception is the indicator of age which joined the second factor with negative coefficient of interrelation. It can be explained with the fact that in our research young athletes were stronger. The indicator of strength of a nervous system (quantity of mistakes at execution of the test on speed of reaction with feedback $)(r=-0,55)$. It is determined that the indicator of strength of a nervous system correlates with indicators of physical strength. Athletes have strength of a nervous system and physical strength as integrated 
implications of the general psychophysical structure of organism. Based on the above stated data, the second factor was called "Strength" (fig. 1).

The third factor included indicators $(9,4 \%$ of general total dispersion): average value of time reaction to a sound $(r=-0,94)$, jump height $(r=0,75)$, an error of reproduction of intervals of $1 \mathrm{sec}$ time $(\mathrm{r}=-0,74)$ (tab. 1). The indicators characterizing the speed of reaction and explosive strength were part of the second factor. Therefore the third factor was called "Speed" (fig. 1).

The fourth factor included only two indicators $(9,2 \%$ of general total dispersion): coefficient of heart rate variations) and average value of time of reaction of the choice $(r=0,64)$, choice reaction time indicators, quantity of mistakes, the general time of execution of the test and time of an exit to the minimum exposition of a signal when testing in the feedback mode $(\mathrm{r}=0,57-0,51)$ (tab. 1).

The obtained data witness that the increasing of activity of parasympathetic branch of the autonomic nervous system reduced the speed of reaction of choice. It is natural reflection of ability to the general relaxation of an organism. In this regard the fourth factor was called “parasympathicotonia” (fig. 1).

The table 1 and the figure 1 witness that major impact to total dispersion is made by the first and second factors. It is logical to conclude that indicators of nervous system reactivity and indicators of strength abilities development are the most significant in structure of athletes' fitness. Indicators of high-speed endurance and ability to relax are less significant. It is expressed in a parasympathicotonia.

Further the individual factorial structure of athletes' fitness was defined. The percentage values of each factor's display at each athlete (tab. 2) were defined for this purpose.

The table 2 and the figure 2 demonstrate that all athletes have different display of various factors. It witnesses about existence of essential individual differences. It has to be shown in various styles of performances and necessity of application of individual programs of athletes' training. It is possible to define athletes with major display of a factor 1 - "sympathicotonia" (athlete № 6), with the major display of a factor 2 - "Strength" (athlete № 3), with major display of a factor 3 - "Speed" (athlete № 2), with major display of a factor "parasympathicotonia” (athlete № 9) (fig. 2).

Table 1. The matrix of indicators' components of qualified athletes (man) testing * $(n=19)$

\begin{tabular}{|c|c|c|c|c|}
\hline \multirow{4}{*}{ Indicators } & \multicolumn{4}{|c|}{ № of factors, contribution in general dispersion } \\
\hline & & & & \\
\hline & 1 & 2 & 3 & 4 \\
\hline & $28,6 \%$ & $28,5 \%$ & $9,4 \%$ & $9,2 \%$ \\
\hline HBR in rotation on Barany chair, rates per $\mathrm{min}^{-1}$ & 0,95 & & & \\
\hline $\begin{array}{l}\text { HBR of renewal after } 90 \mathrm{sec} \text { after work, rates per } \\
\min ^{-1}\end{array}$ & 0,94 & & & \\
\hline HBR after rotation on Barany chair, rates per min $^{-1}$ & 0,93 & & & \\
\hline Mo RR-intervals, sec & 0,89 & & & \\
\hline $\begin{array}{l}\text { HBR after } 10 \mathrm{sec} \text { after rotation on Barany chair, } \\
\text { rates per } \mathrm{min}^{-1}\end{array}$ & 0,88 & & & \\
\hline $\mathrm{HBR}$ at rest, rates per $\mathrm{min}^{-1}$ & 0,68 & & & \\
\hline Choice reaction time with feedback, msec & $-0,57$ & & & \\
\hline $\begin{array}{l}\text { Choice reaction time with feedback, total time of } \\
\text { test execution, sec }\end{array}$ & $-0,53$ & & & \\
\hline $\begin{array}{l}\text { Choice reaction time minimum time of signal } \\
\text { exposition, } \mathrm{msec}\end{array}$ & $-0,51$ & & & \\
\hline Age (years) & & $-0,92$ & & \\
\hline Body mass (kg) & & 0,85 & & \\
\hline Wrist strength, $\mathrm{kg}$ & & 0,81 & & \\
\hline Back strength, kg & & 0,72 & & \\
\hline Body length, $\mathrm{cm}$ & & 0,68 & & \\
\hline Choice reaction with feedback, mistakes, quantity & & $-0,55$ & & \\
\hline Time of reaction to sound (msec) & & & $-0,94$ & \\
\hline High jump from the spot $(\mathrm{cm})$ & & & 0,75 & \\
\hline $\begin{array}{l}\text { Mistake in reproduction of time interval's } 1 \mathrm{sec} \text {, } \\
\mathrm{sec}\end{array}$ & & & $-0,74$ & \\
\hline Variation range of RR-intervals, sec & & & & 0,96 \\
\hline Choice reaction time, average values, sec & & & & 0,64 \\
\hline
\end{tabular}

* Note: the rotation of matrix is carried out by Varimax method. 


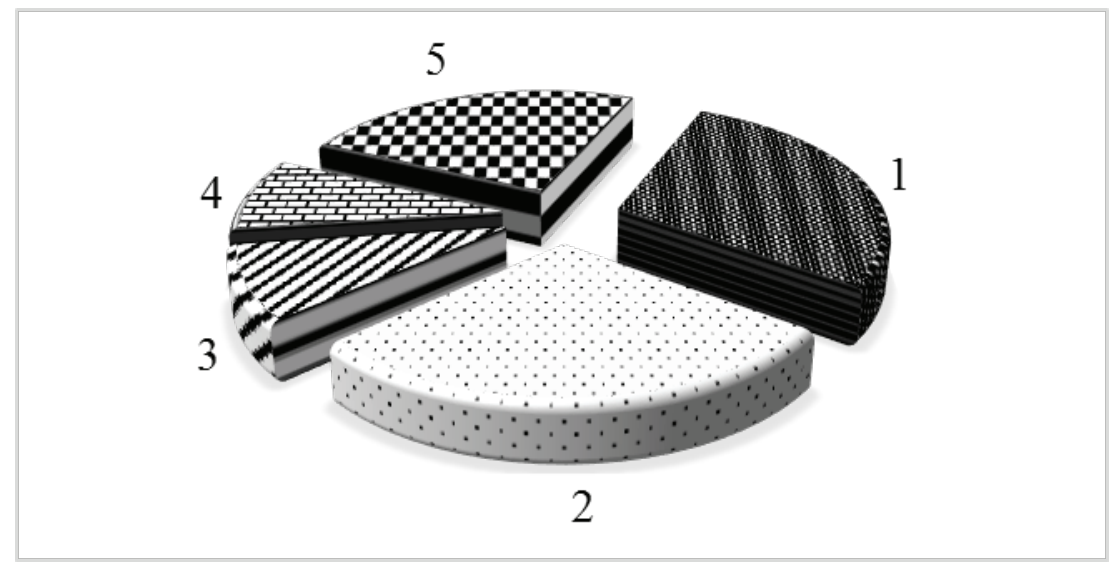

Fig. 1. Factorial structure of athletes' fitness $(n=19)$ ( 4 factors are defined): 1 - Factor of "Sympathicotonia", 28,6\%; 2 Factor "Strength", 28,5\%; 3 - Factor "Speed", 9,4\%; 4 - Factor of "Parasympathicotonia", 9,2\%; 5 - Other factors, 24,3\%

Table 2. Individual display of factors in structure of athletes (male) fitness' (\% of the maximum display of factor in selection) $(n=19)$

\begin{tabular}{lllll}
\hline Athlete's № & $\begin{array}{l}\text { Factors } \\
\text { Sympathicotonia }\end{array}$ & Strength & Speed & Parasympathicotonia \\
\hline 1 & 88,89 & 32,22 & 61,11 & 52,22 \\
2 & 77,78 & 11,11 & 100 & 77,78 \\
3 & 66,67 & 33,33 & 33,33 & 33,33 \\
4 & 63,33 & 47,78 & 58,89 & 61,11 \\
5 & 55,56 & 78,89 & 55,56 & 94,44 \\
6 & 92,22 & 44,44 & 66,67 & 55,56 \\
7 & 100 & 46,53 & 77,78 & 66,67 \\
8 & 41,11 & 55,56 & 42,22 & 88,89 \\
9 & 54,44 & 66,67 & 44,44 & 100 \\
\hline
\end{tabular}

For combined performances it is possible to select athletes with similar qualities (representatives of one cluster) and with different qualities (representatives of different clusters). For example, the athlete with the major display of a factor "Strength" can be combine (to make a team of athletes) to athletes with the major display of a factor of Sympathicotonia. Also it is possible to combine such athlete with others depending on tasks of the performance program. The athlete with the major display of a factor "Strength" will perform successful in programs with keeping of other athletes. Thus, determination of personal factorial structure of athletes' fitness permits to evaluate objectively options of athletes completing in groups. It gives the opportunity of effective teams' formation for competitive performances in different categories.

\section{Discussion}

The analysis of literature and own results of the research revealed that this research is the first from the point of view of theoretical and methodical bases development of teams' formation for performances in different competitive categories; integral training of athletes in sport aerobics. Nowadays there is insufficient quantity of scientific research in the field of individual approach to the training process in sport aerobics. At the same time authors concern the research and development of separate parameters of athletes training. The authors do not consider process of team's formation and integral preparation from the point of view of the analysis of a wide complex of fitness indicators [39]. That's why the subject and object, the purposes and tasks of research are new and relevant.

Prior to this research of teams' formation for performances in different competitive categories and integral training of athletes were considered only as peripheral issue. The teams' formation did not consider the principles, an algorithm, and analysis tools of indicators and specific techniques of training process optimization. From this point of view our research is new. Our research is important not only for the theory and practice of sport training. This research is also important for other sciences connected with a study of the person - pedagogics, psychology, psycho-physiology, etc.

In our work the process of teams' formation is based on determination of individual factorial structure of each athlete's fitness. Therefore creation of an algorithm of teams formation in sport aerobics is a new problem, developed for the first time. The carried-out analysis of scientific literature data [39] determined that most of authors consider the principle of team's combination and individual fitness as one of the main principles. At 


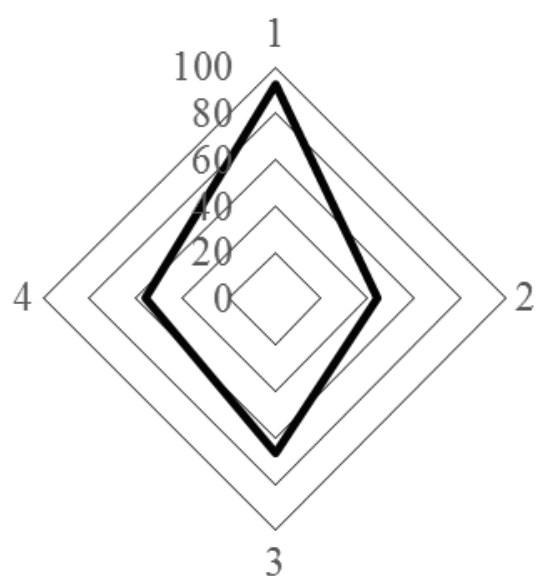

Athlete № 6

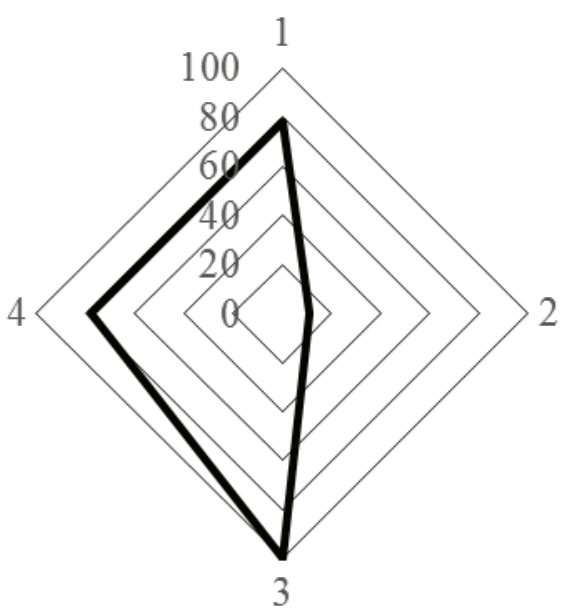

Athlete № 2

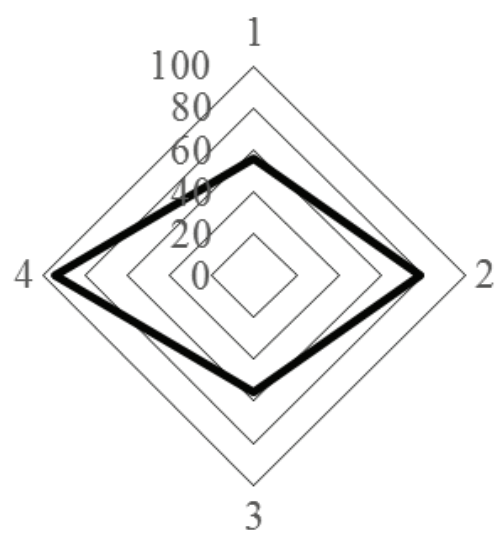

Athlete № 9

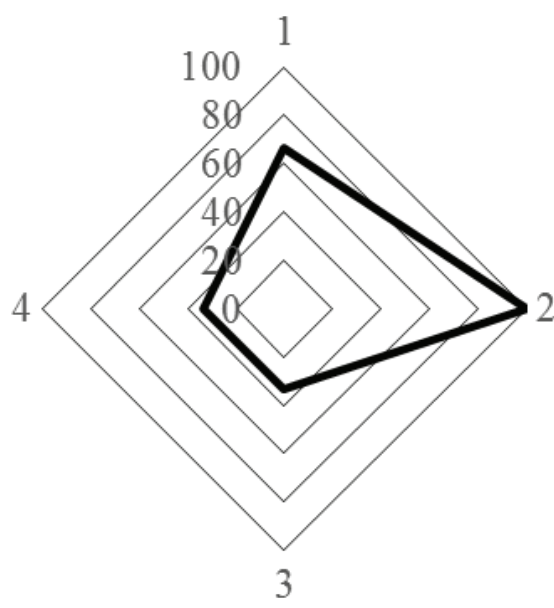

Athlete № 3

Fig. 2. Personal factorial structure of the functional and psychophysiological capabilities at athletes: 1 - Factor of "Sympathicotonia"; 2 - Factor "Strength"; 3 - Factor "Speed"; 4 - Factor of "Parasympathicotonia".

the same time, in cyclic sports there are already some scientific works concerning to concrete recommendations about creation of educational and training process for each athlete. In sport aerobics there are only a few theoretical, methodical and organizational bases of team and individual approach combination to the training process of athletes.

That's why our research has a new direction. In this case the principle of combination of team and individual training of athletes becomes a system which has the structure, algorithms and mathematical apparatus.

From the analysis of scientific literature data [40, 41] was revealed that the problem of individual distinctions has rich history and is beyond far the theory and a technique of physical training and sport. From this point of view our work is expansion and addition of available knowledge of individual human nature. Our research gives the chance of application of athletes' specific features for creation of various groups depending on tasks of educational and training process [42].

In our research the methodology for individualization in game sports is used $[43,44]$. From this point of view the system of a team's combination and individual approach to process of athletes training in aerobics is expansion and addition of results of other researches [45-48]. In our research the approaches to the training process' planning are presented with consideration of specific features of factorial structure of athletes' fitness, their psychophysiological and functional features.

In sport aerobics athletes form groups for performances in various competitive categories. The success of performances at competitions depends on optimum selection of structure of such teams. It should be noted that in recommendations for training of athletes in aerobics questions of individual athletes' distinctions aren't revealed (psychological, physiological, psychophysiological). This question is important for ensuring success of performances at competitions. Therefore the offered methods of the leading factors' definition are represented the new approach to individualization fitness' problem.

On the basis of generalization of scientific literature data, results of own experiments and carrying out the general theoretical-analytical research we have developed 
the general scheme of ways of team's combination and individual training of athletes. Such scheme is already used in game sports [25]. It looks as follows.

The first direction of this series of researches provides creation of an algorithm of mathematical systematization and processing of a wide range of the indicators reflecting the separate parties of athlete's fitness and condition. This direction considers a condition of the athlete or group of athletes in separate time point.

This direction supposes the determination of group and individual structure of athletes' fitness. Then by means of the cluster analysis athletes form groups by fitness similarity.

The second direction of scientific providing of fitness process' individualization is connected with the analysis of the factors causing individual dynamics of athletes' competitive effectiveness. This direction presupposes the creation of regression models of dynamics regularities of athletes' competitive efficiency and application of these models for the forecast of competitive result and management of educational and training process. In our research this direction is reflected in individual approach to the training process creation in a year cycle. We considered increasing and decreasing of competition form's level.

The third direction of researches is connected with development of the interactive technologies [41] permitting to increase the various aspects of training process to qualitatively new level.

On the basis of researches' results of three directions are created the team and individual programs of athletes training.

Thus, the training of athletes in aerobics is based on the system approach. It is extension of scientific literature data and for the first time obtained data in sport aerobics.

\section{Conclusions}

1. The algorithm of teams' formation in sport aerobics for performances in various competitive categories is developed. The factorial and cluster analysis were used in this approach. The algorithm contains all stages of the standard procedure of the factorial and cluster analysis. In the factorial analysis individual factorial values for creation of complete characteristics of each athlete were revealed. The general and individual factorial structure of complex fitness of athletes is defined.

2. For the combined performances it is possible to select athletes according to the similar and different qualities. Determination of individual factorial fitness' structure permits to evaluate objectively options of athletes groups' formation. It permits forming effective team for competitive performances in various categories.

\section{Acknowledgments}

The research is conducted according to:

- the consolidating plan of research work in the sphere of physical culture and sport for 2011-2015 on a subject 2.4 «Theoretical and methodical bases of individualization in physical training and sport» (№ of the state registration 0112U002001);

- the research work of Ministry of Education and Science of Ukraine for 2013-2014. «Theoretical and methodical bases of application the information, pedagogical and medical-biological technologies for formation of healthy lifestyle» (№ of the state registration 0113U002003);

- the research work of Ministry of Education and Science of Ukraine for 2015-2016. «Theoretical and methodical bases of means application the information, pedagogical, medical-biological orientation for motor and spiritual development and formation of healthy lifestyle» (№ of the state registration 0115U004036).

- the research work of Ministry of Education and Science of Ukraine for 2017-2018. «Theoretical and methodical bases of application of information, medicalbiological and pedagogical technologies for realization of individual physical, intellectual and spiritual potential and formation of healthy lifestyle» (№ of the state registration 0117U000650).

\section{Conflict of interests}

The author declares that there is no conflict of interests.

\section{References}

1. Shypulo IP. Influence employment by improving aerobics on motor readiness of girls. Physical education of students, 2015; 19(1): 67-71. doi:10.15561/20755279.2015.0110

2. Beliak YuI, Zinchenko NM. Dosing method of physical activity in aerobics classes for students. Physical education of students, 2014; 18(5): 8-13. doi:10.15561/20755279.2014.0502

3. Bryukhanova NA, Bulgakova OV, Mokrova TI, Bogashchenko YA. Determination of possibilities of the use of high-intensive trainings facilities on lessons health aerobics. Physical education of students, 2013; 17(2): 25-29. doi:10.6084/m9.figshare. 156376

4. Gurieieva AM, Klopov RV. Factor structure of physical state of female students of higher education institution. Pedagogics, psychology, medical-biological problems of physical training and sports, 2014; 18(7): 7-11. doi:10.6084/ m9.figshare. 1015378
5. Golod N R. Principles of developing a well-rounded program of physical rehabilitation for female students in the special medical group with consideration of physical activity impairment. Pedagogics, psychology, medical-biological problems of physical training and sports, 2015; 19(5): 9-15. doi:10.15561/18189172.2015.0502

6. Chen H. SWOT Analysis Deeply Promote Aerobics Marketorientation Development Under China Sport Service Certification. 7th International Symposium on Education Innovation Location: Henan Polytechn Univ, Beijing; 2014. P.289-94 p.

7. Fan C. Biomechanical Study of Jump Ability for Aerobics Sports Based on Single Chip Technology. Applied Mechanics and Materials, 2014;484-485:408-412.

8. Hu CF, Xiang Y. Analysis the Relationship of System. Theory and Aesthetics of the Aerobics, 2013;45:101-104.

9. Jiang G, Ji Z, Li X, Guo L. Biomechanical Analysis on Free Falls and Straddle Jump to Push up Difficulty Elements in 
Sports Aerobics. 9th China National Convention on Sport Science Location: Shanghai; 2012. P. 114-7.

10.Li A. An Analysis of Physiological and Psychological Rehabilitation from Injuries of Sport Aerobics Athletes. Advances in Education Research. 2014;63:206-209.

11.Li C, Zhou A, Qian GR, Wang Y. Factor Analysis of Ankle Injury in Aerobics Training and Prevention Treatment. 9th China National Convention on Sport Science Location: Shanghai, 2012. P. 450-452.

12.Huang WY, Zhang JA, Liu XX, Yang NE. Factors to Influence HRV of Aerobics Athletes under Increasing Load. 21st PanAsian Congress of Sports and Physical Education Location: Jiangxi Normal Univ, Nanchang; 2010. P. 49-52.

13.Sang GQ. A Sociocultural Study of the Rise of Aerobics. 2nd International Conference on Education and Sports Education Location: Guangzhou; 2011. P. 188-191.

14.Shi WY. Research on the Development and Application of Aerobics Network Teaching Courseware. 8th International Symposium on Computer Science in Sport (IACSS 2011) Location: Shanghai; 2011. P. 417-422.

15.Wang M. Discussion of the Relationship between Core Power Training and Physical Control of Aerobics Athletes. In: Zhang H, editor. 2016 6th Ese International Conference on Sports and Social Sciences. Lecture Notes in Management Science. 2016;59: p. 153-5.

16.Zarebska A, Jastrzebski Z, Moska W, Leonska-Duniec A, Kaczmarczyk M, Sawczuk M, et al. The AGT Gene M235T Polymorphism and Response of Power-Related Variables to Aerobic Training. Journal of Sports Science and Medicine. 2016;15(4):616-24.

17.Yan FF. Artistic Arrangement of Complete Sets of Competitive Aerobics Taking the Three - Person Aerobics as an Example. Advances in Education Research. 2016;94:334339.

18.Xiang FF, Shi P. The Role of Core Strength in Body Posture of Aerobics. Advances in Education Research. 2016;92:97100.

19.Mayorga-Vega D, Montoro-Escano J, Merino-Marban R, Viciana J. Effects of a physical education-based programme on health-related physical fitness and its maintenance in high school students: A cluster-randomized controlled trial. European Physical Education Review. 2016;22(2):243-59.

20.Nyberg G, Meckbach J. Exergames “as a teacher' of movement education: exploring knowing in moving when playing dance games in physical education. Physical Education and Sport Pedagogy. 2017;22(1):1-14.

21.Chen H, Sun HC, Dai J, Griffin M. Relationships Among Middle School Students’ Expectancy Beliefs, Task Values, and Health-Related Fitness Performance. Journal of Teaching in Physical Education. 2017;36(1):40-9.

22.Iermakov SS, Podrigalo LV, Jagiello W. Hand-grip strength as an indicator for predicting the success in martial arts athletes. Archives of Budo. 2016;12:179-86.

23.Giovanelli N, Taboga P, Rejc E, Lazzer S. Effects of strength, explosive and plyometric training on energy cost of running in ultra-endurance athletes. European Journal of Sport Science. 2017;17(7):805-13.

24.Sindiani M, Eliakim A, Segev D, Meckel Y. The effect of two different interval-training programmes on physiological and performance indices. European Journal of Sport Science. 2017;17(7):830-7.

25.Iermakov SS, Arziutov GN, Jagiello W. Quick training of students to judo techniques. Archives of Budo. 2016;12:1524.

26.Kriventsova I, Iermakov S, Bartik P, Nosko M, Cynarski W. Optimization of students-fencers' tactical training. Ido
Movement for Culture-Journal of Martial Arts Anthropology, 2017; 17(3), 21-30. doi:10.14589/ido.17.3.3

27. Arziutov G, Iermakov S, Bartik P, Nosko M, Cynarski WJ. The use of didactic laws in the teaching of the physical elements involved in judo techniques. Ido Movement for CultureJournal of Martial Arts Anthropology, 2016;16(4):21-30. doi:10.14589/ido.16.4.4

28.Khudolii OM, Ivashchenko OV, Iermakov SS, Rumba OG. Computer simulation of Junior gymnasts' training process. Science of Gymnastics Journal, 2016;8(3):215-228.

29.Podrigalo LV, Iermakov SS, Jagiełł W. Special indices of body composition as a criterion of somatic development of martial arts practitioners. Arch Budo Sci Martial Art Extreme Sport 2017; 13: 5-12.

30.Osipov AY, Kudryavtsev MD, Iermakov SS, Jagiello W. Topics of doctoral and postdoctoral dissertations devoted to judo in period 2000-2016 - the overall analysis of works of Russian experts. Archives of Budo, 2017; 13: 1-10.

31.Bliznevsky AA, Kudryavtsev MD, Iermakov SS, Jagiello W. Formation of active-effective attitude of 12-13 years' judo athletes to sports functioning in competition period. Archives of Budo. 2016;12:101-15.

32.Osipov AY, Kudryavtsev MD, Iermakov SS, Jagiello W. Criteria for effective sports selection in judo schools - on example of sportsmanship's progress of young judo athletes in Russian Federation. Archives of Budo, 2017; 13: 179-187.

33.Rosselli AC, Singer JN. Influential Factors that Contribute to Black Golfers' Participation at the Elite-Level. Physical Activity Review. 2017;5:132-45. doi:10.16926/par.2017.05.18

34.Dziadek B, Iskra J, Przednowek K. Running preparation and the final decathlon score in terms of sports career development. Physical Activity Review. 2016;4:115-23. doi:10.16926/par.2016.04.14

35. Wasik J, Gora T. Impact of target selection on front kick kinematics in taekwondo - pilot study. Physical Activity Review. 2016;4:57-61. doi:10.16926/par.2016.04.07

36. Mata JD, Oliver JM, Jagim AR, Jones MT. Sex Differences in Strength and Power Support the Use of a Mixed-Model Approach to Resistance Training Programing. Strength and Conditioning Journal. 2016;38(2):2-7. doi:10.1519/ ssc. 0000000000000182

37.Korobeynikov G, Mazmanian K, Korobeynikova L, Jagiełło W. Psychophysiological states and motivation in elite judokas. Archives of Budo, 2010;6(3):129-136.

38.Kozina Z, Prusik K, Görner K, Sobko I, Repko O, Bazilyuk T, Kostiukevych V, Goncharenko V, Galan Y, Goncharenko O, Korol S, Korol S. Comparative characteristics of psychophysiological indicators in the representatives of cyclic and game sports. Journal of Physical Education and Sport, 2017;17(2):648 - 655.

39.Andreu JMP. Sport and personal variables in the occurrence of sports injuries. Differences between individual and team sports. Retos-Nuevas Tendencias En Educacion Fisica Deporte Y Recreacion. 2015;28:21-25.

40.Zhanneta K, Irina S, Tatyana B, Olena R, Olena L, Anna I. The applying of the concept of individualization in sport. Journal of Physical Education and Sport. 2015;15(2):172177. doi:10.7752/jpes.2015.02027

41.Kozina ZhL, Ol'khovyj OM, Temchenko VA. Influence of information technologies on technical fitness of students in sport-oriented physical education. Physical education of students, 2016; 20(1): 21-28. doi:10.15561/20755279.2016.0103

42.Sobko I. An innovative method of managing the training process of qualified basketball players with hearing impairment. Journal of Physical Education and Sport, 
2015;15(4):640-645: doi:10.7752/jpes.2015.04097

43.Kozina ZhL, Prusik Krzysztof, Prusik Katarzyna. The concept of individual approach in sport. Pedagogics, psychology, medical-biological problems of physical training and sports, 2015; 19(3): 28-37. doi:10.15561/18189172.2015.0305

44.Kozina ZL, Jagiello Wladyslaw, Jagiello Marina. Determination of sportsmen's individual characteristics with the help of mathematical simulation and methods of multidimensional analysis. Pedagogics, psychology, medicalbiological problems of physical training and sports, 2015; 19(12): 41-50. doi:10.15561/18189172.2015.1207

45.Kozina ZL, Iermakov SS, Kadutskaya LA, Sobyanin FI, Krzeminski M, Sobko I N, Ryepko OA. Comparative characteristic of correlation between pulse subjective indicators of girl students' and school girls' reaction to physical load. Physical education of students, 2016; 20(4): 24-34. doi:10.15561/20755279.2016.0403

46.Jagiello W, Sawczyn S, Jagiello M. The subjective profile of positive health and survival abilities in women differing as to physical activity. Archives of Budo. 2012;8(4):219-24.

47.Sawczyn S, Mishchenko V, Moska W, Sawczyn M, Jagiello M, Kuehne T, et al. Strength and aerobic training in overweight females in Gdansk, Poland. Open Medicine. 2015;10(1):152-62.

48.Wolyniec W, Ratkowski W, Urbanski R, Bartoszewicz M, Wolyniec Z, Siluk D, et al. Urinary kim-1 but not urinary ngal is increased after short maximal exercise. Nephrology Dialysis Transplantation. 2016;31:149-149.

\section{Information about the authors:}

Shepelenko T.V.; http://orcid.org/0000-0002-6401-2364; shepelenko_tatyana@ukr.net; Ukrainian State University of Railway Transport; Feuerbach square 7, Kharkov, 61050, Ukraine.

Kozina Zh.L.; http://orcid.org/0000-0001-5588-4825; Zhanneta.kozina@gmail.com; H.S. Skovoroda Kharkiv National Pedagogical University; Alchevskyh str. 29, Kharkov, 61002, Ukraine.

Cieślicka Mirosława; http://orcid.org/0000-0002-0407-2592; cudaki@op.pl; Kazimierz Wielki University in Bydgoszcz; Chodkiewicza str. 30, 85-064 Bydgoszcz, Poland.

Prusik Krzysztof; http://orcid.org/0000-0001-7534-675X; prusik@hot.pl; Gdansk University of Physical Education and Sport; Kazimierza Gorskiego 1, 80-336 Gdansk, Poland.

Muszkieta Radosław; http://orcid.org/0000-0001-6057-1583; radek@muszkieta.com; Nicolaus Copernicus University in Torun; Jurija Gagarina 11, 87-100 Toruń, Poland.

Sobko I.N.; http://orcid.org/0000-0002-4920-9775; sobko.kh@mail.ru; Kharkov National Economic University; Lenina boulevard 9a, 61001, Kharkov, Ukraine.

Ryepko O.A.; http://orcid.org/0000-0001-6879-6015; chigiki.ua@mail.ru; Kharkov National Pedagogical University; Altshevskih str. 29, Kharkov, 61002, Ukraine.

Bazilyuk T.A.; http://orcid.org/0000-0002-6244-6302; baziluk@rambler.ru; Kiev National University of Technology and Design; st. Nemirovich-Danchenko, 2, Kiev, 01000, Ukraine.

Polishchuk S.B.; http://orcid.org/0000-0001-8275-4567; staspolischuk@mail.ru; Kharkov National Pedagogical University; Altshevskih str. 29, Kharkov, 61002, Ukraine.

Osiptsov A.V.; http://orcid.org/0000-0002-1640-2632; osipcov_andrey@mail.ru; Mariupol State University; Budivelnykiv Ave., 129a, Mariupol, 87500, Ukraine.

Kostiukevych V.M.; http://orcid.org/0000-0002-6215-764X; v.m.kost@mail.ru; Mykhailo Kotsyubynskyi Vinnitsa State Pedagogical University; Ostrozky str. 32, Vinnitsa21100, Ukraine.

Cite this article as: Shepelenko TV, Kozina ZhL, Cieślicka M, Prusik K, Muszkieta R, Sobko IN, Ryepko OA, Bazilyuk TA, Polishchuk SB, Osiptsov AV, Kostiukevych VM. Factorial structure of aerobics athletes' fitness. Pedagogics, psychology, medicalbiological problems of physical training and sports, 2017;21(6):291-300. doi:10.15561/18189172.2017.0606

The electronic version of this article is the complete one and can be found online at: http://www.sportpedagogy.org.ua/index.php/PPS/issue/archive

This is an Open Access article distributed under the terms of the Creative Commons Attribution License, which permits unrestricted use, distribution, and reproduction in any medium, provided the original work is properly cited (http://creativecommons.org/licenses/by/4.0/deed.en).

Received: 05.09.2017

Accepted: 01.10.2017; Published: 05.11.2017 